\title{
Simultaneous Determination of Fluoroquinolones and Sulfonamides Originating from Sewage Sludge Compost
}

\author{
K. Kipper, ${ }^{1}$ M. Lillenberg, ${ }^{2}$ K. Herodes, ${ }^{1}$ L. Nei, ${ }^{3}$ and E. Haiba ${ }^{3}$ \\ ${ }^{1}$ Institute of Chemistry, University of Tartu, Tartu, Estonia \\ ${ }^{2}$ Estonian University of Life Sciences, Tartu, Estonia \\ ${ }^{3}$ Tartu College, Tallinn University of Technology, Tartu, Estonia \\ Correspondence should be addressed to K. Kipper; karin.kipper@gmail.com
}

Received 20 February 2017; Revised 1 May 2017; Accepted 11 May 2017; Published 12 June 2017

Academic Editor: Sandra Babic

Copyright (C) 2017 K. Kipper et al. This is an open access article distributed under the Creative Commons Attribution License, which permits unrestricted use, distribution, and reproduction in any medium, provided the original work is properly cited.

\begin{abstract}
A simultaneous method for quantitative determination of traces of fluoroquinolones (FQs) and sulfonamides (SAs) in edible plants fertilized with sewage sludge was developed. The compounds were extracted from the plants by rapid and simple liquid extraction followed by extracts clean-up using solid phase extraction. The eluent additive 1,1,1,3,3,3-hexafluoro-2-propanol was used for liquid chromatographic detection to achieve separation of structurally similar antimicrobials like ciprofloxacin and norfloxacin. Identification and quantification of the compounds were performed using high-performance liquid chromatography with electrospray ionization mass spectrometry in selected reaction monitoring mode. Method was validated and extraction recoveries of FQs and SAs ranged from $66 \%$ to $93 \%$. The limit of quantifications was from $5 \mathrm{ng} / \mathrm{g}$ in the case of ofloxacin to $40 \mathrm{ng} / \mathrm{g}$ for norfloxacin. The method precision ranged from $1.43 \%$ to $2.61 \%$. The developed novel method was used to evaluate the plats antimicrobial uptake (potato (Solanum tuberosum L.), carrot (Daucus carota L.), lettuce (Lactuca sativa L.), and wheat (Triticum vulgare L.)) from soil and migration of the analytes inside the plants.
\end{abstract}

\section{Introduction}

The increase of the yearly production of sewage sludge compost containing human and veterinary antimicrobials has led to antimicrobial resistance being one of the top health challenges in the 21st century [1]. One of the largest and most diverse microbial habitats on Earth is soil, a vast repository of the antimicrobial resistance genes between soil bacteria and clinical pathogens [2].

When antimicrobials are eliminated from the human body, they can be excreted in their native form or as metabolites [3]. Since antimicrobials are developed to have a specific mode of action, even low levels of these drugs in edible plants can cause effects in organisms [4].

Several studies have demonstrated that the two most important sources through which toxic compounds reach the environment are sewage sludge and compost, which are often used in agriculture [5-9]. More generally, pharmaceuticals move into the sewage system and to waste water treatment plants [10]. The nutrition-rich sewage sludge and compost can be used as fertilizers for plants. The increasing proportions of administered drugs and personal care products are alarming because the compound releases into the environment are not controlled [11,12] and this is a potential threat to the environment [13-15]. It is worrisome that pharmaceutical compounds may potentially enter edible food plants that have been fertilized with sewage sludge compost $[9,16-18]$.

The risks from the fertilizer should be evaluated carefully. Exposure to pharmaceuticals via plant-derived foodstuffs is usually low and effects on human health are in most cases unlikely. This route of exposure may, however, be more significant for a small number of highly toxic medicines or in situations where long-term low-level exposure could elicit subtler effects (e.g., promotion of antibacterial resistance or endocrine disruption) [19]. A chemical can undergo various structural changes by a multitude of biotic and nonbiotic processes after its introduction into the environment. Structural transformations may also be a result of effluent treatment $[4,20-26]$. The maximum residue levels (MRL) are set only for food of animal origin, milk and meat $[27,28]$. 
Analytical methods have been developed and applied for the determination of different antimicrobials in sewage sludge and its compost, biosolids, and sludge-treated soil [2938]. Many antimicrobials, known to be persistent in soils fertilized with sewage sludge compost, can accumulate into food plants [39-46]. The pharmaceuticals accumulated in the food plants may generate resistant bacteria in human and animal organisms. The groups of antimicrobials of interest are well-known, but it is a complicated task to separate structurally similar compounds in a reversed-phase LC (liquid chromatography) system. On the other hand, the concentrations in residue levels are very low and therefore improved MS (mass spectrometry) sensitivity is more than welcome. The aim of the present study was to use an eluent additive 1,1,1,3,3,3-hexafluoroisopropanol (HFIP) to improve LC separation significantly with alternative selectivity in C18 stationary phase and enhance MS detection of fluoroquinolones (FQs) and sulfonamides (SAs) in small concentration levels to quantify them in food plant samples. These drugs were selected according to three criteria: (1) their stability in soil [47], (2) their potential to accumulate into plants $[39,46]$, and (3) their presence in sewage sludge and its compost [48].

For the prevention of the development of microbial resistance of humans and animals, the concentration of antimicrobials in compost must be significantly below $1 \mu \mathrm{g} / \mathrm{kg}$, securing the relevant soil concentrations at $0.01-0.1 \mu \mathrm{g} / \mathrm{kg}$ [49]. In our previous work [16], the highest detected concentrations of the antimicrobial norfloxacin (NOR), ciprofloxacin (CIP), ofloxacin (OFL), sulfamethoxazole (SMX), and sulfadimethoxine (SDM) in sewage sludge and its compost were as shown in Table 1.

\section{Materials and Methods}

2.1. Chemicals. Pharmaceuticals were purchased from Riedelde-Haën (Seelze, Germany): three FQs, CIP (purity 99.8\%), NOR (purity 99.9\%), and OFL (purity 99.3\%); two SAs, SDM (purity 99.4\%) and SMX (purity 99.9\%). Acetonitrile and methanol were obtained from J.T. Baker (Deventer, Netherlands), HPLC grade formic acid, and ammonia from Riedel-de-Haën. HFIP was purchased from Sigma (St. Louis, MO, USA). All solvents were of reagent grade or higher quality. Water was purified $\left(18.2 \mathrm{M} \Omega \times \mathrm{cm}\right.$ at $25^{\circ} \mathrm{C}$ and a TOC value below $3 \mathrm{ppb}$ ) in-house using a Milli-Q Plus system from Millipore (Bedford, USA). Hydrophilic-lipophilic balanced (HLB) solid phase extraction (SPE) cartridges (Oasis HLB $(60 \mu \mathrm{m}), 500 \mathrm{mg} / 6 \mathrm{~mL})$ were purchased from Waters (Milford, MA, USA).

The selection of antimicrobials was made according to preliminary pilot study on antimicrobials usage and presence in the sewage sludge samples [48], their stability in the soil and potential degradation during the composting procedure [16], and their uptake from the soil by plants [46].

2.2. Plant Samples. For the experiments with plants, the antimicrobials were spiked into the soil in which the plants were grown [49]. Aqueous solutions of the studied pharmaceuticals were mixed with soil. The final concentration of each
TABLE 1: Occurrence of antimicrobials $(\mu \mathrm{g} / \mathrm{kg})$ in sewage sludge and its compost (illustrative data).

\begin{tabular}{lccccc}
\hline Antimicrobial media & NOR & CIP & OFL & SMX & SDM \\
\hline Sewage sludge & 162 & 426 & 39 & 6 & 20 \\
Compost & 22 & 20 & 3 & 1 & 4 \\
\hline
\end{tabular}

pharmaceutical was $10 \mathrm{mg}$ per kg of dry soil. To ensure better dissolution of the studied pharmaceuticals, fluoroquinolones were dissolved in $2 \mathrm{ml}$ of $0.1 \mathrm{mM}$ ammonium acetate buffer solution with pH 2.8 and sulfonamides were dissolved in $2 \mathrm{ml}$ of $0.3 \mathrm{M} \mathrm{NaOH}$. Potatoes (Solanum tuberosum L.), carrots (Daucus carota L.), lettuce (Lactuca sativa L.), and wheat (Triticum vulgare L.) were grown in the presence of five antimicrobials commonly present in sewage sludge (CIP, NOR, OFL, SDM, and SMX). The potato tubers and plant seeds were planted into the pots, with one tuber or 35 seeds in each pot. The plants were cultivated in a greenhouse under natural light conditions for 120 days after planting (lettuce, 70 days). The soil was weighed, and aqueous solutions of the studied pharmaceuticals were mixed with the soil. The final concentration of each pharmaceutical was $0.01,0.1,0.5,1$, and $10 \mathrm{mg} / \mathrm{kg}$ (dry weight). Three parallel experiments were conducted for each concentration of antimicrobials. In reference experiments, plants were cultivated in antimicrobialfree soils. The plants were collected and washed carefully. Potatoes and carrots were chopped into ca $1 \mathrm{~cm}^{3}$ pieces. Then the plants were dried at room temperature in the darkness and after that milled for analyses, using Knifetec 1095 Sample Mill (Foss) and a common coffee mill. The size of the particles of the powder was $<1 \mathrm{~mm}^{3}$. The milled samples were dewatered in a thermostat at $45^{\circ} \mathrm{C}$ for 24 hours using thermostat Binder KB 115 and stored in hermetic plastic bags for three weeks at $-80^{\circ} \mathrm{C}$ (using refrigerator Sanyo MDF$\mathrm{U} 54 \mathrm{~V})$ before analysis.

2.3. Sample Preparation. $250 \mathrm{mg}$ of dried plants (grains, roots, or leaves) was extracted with $10 \mathrm{~mL}$ of a $1: 1(\mathrm{v} / \mathrm{v}) \mathrm{mix}-$ ture of acetonitrile and $1 \%$ acetic acid, then homogenized with laboratory homogenizer DIAX 900 (Heidolph Instruments, Germany) at 25,000 rpm, sonicated $\left(5^{\prime}\right)$, vortexed $\left(1^{\prime}\right)$, and centrifuged at $8000 \mathrm{rpm}$. The supernatant was then separated and dried by nitrogen stream to remove acetonitrile. Approximately $15 \mathrm{~mL}$ of $1 \%$ acetic acid was added to the $1 \mathrm{~mL}$ of evaporation residue [49].

The extract collected with liquid extraction was cleaned up with solid phase extraction (SPE). Antimicrobials, CIP, NOR, OFL, SDM, and SMX, were extracted using HLB cartridges. For the SPE procedure, the vacuum manifold (Agilent Technologies) was used. HLB cartridges were preconditioned with $20 \mathrm{~mL}$ of methanol and $10 \mathrm{~mL}$ of Milli-Q water. The sample was loaded at a rate of $6 \mathrm{~mL} / \mathrm{min}$. After extraction, the compounds were eluted from the cartridges using $12 \mathrm{~mL}$ of methanol. The SPE extracts were evaporated to dryness in polypropylene vials in an N2 stream. Residue was dissolved in $1 \mathrm{~mL}$ of $20 \%$ methanol with buffer solution ( $5 \mathrm{mM} \mathrm{1,1,1,3,3,3-}$ hexafluoro-2-propanol, $\mathrm{pH}$ adjusted to 9.0 with $\mathrm{NH}_{4} \mathrm{OH}$ ). 
2.4. Liquid Chromatography-Mass Spectrometry. Chromatographic separation of the analytes was carried out on the Agilent Series 1100 LC-MSD Trap XCT (Agilent Technologies, Santa-Clara, CA, USA) equipped with a binary pump, a degasser, an autosampler, and a column thermostat. Five antimicrobials were chromatographed using a Waters XBridge C18 column $(150 \mathrm{~mm} \times 3 \mathrm{~mm}, 3.5 \mu \mathrm{m})$ equipped with a Waters Guard Cartridge $(20 \mathrm{~mm} \times 4.6 \mathrm{~mm})$ (Waters, Milford, USA). For detection, a diode array detector and ESIMS were used in series. ESI-MS detection was carried out in positive ion detection mode. Selected reaction monitoring was used. Full MS ${ }^{2}$ spectra were recorded and the following transitions were applied for quantification: OFL $\mathrm{m} / z$ $362 \rightarrow 261,318$; NOR $m / z 320 \rightarrow 302$, 276; CIP $m / z 332 \rightarrow 288$, 314; SMX $m / z 254 \rightarrow 108,188$; SDM $m / z 311 \rightarrow 108,156,218$, 245. Default parameters for ESI and MS were used for all the experiments (nebulizer gas pressure was $40 \mathrm{psi}$, dry gas flow was $10 \mathrm{~L} / \mathrm{min}$, dry gas temperature was $350^{\circ} \mathrm{C}$, capillary voltage was $5000 \mathrm{~V}$, detected mass range was from $\mathrm{m} / z 100$ to 1000 , and target mass for compounds was $m / z$ 350). The LCMS instrument was controlled by Agilent Chemstation for LC 3D rev. A.10.02 (Agilent Technologies) and LC/MSD Trap Control ver. 5.2 (Bruker Daltonik GmbH, Germany). Data analysis was carried out using Chemstation software (Agilent Technologies) and Data Analysis for LC/MSD Trap Version 3.2 (Bruker Daltonik GmbH).

2.5. Chromatographic Conditions. $5 \mathrm{mM}$ HFIP buffer ( $\mathrm{pH}$ adjusted with $\mathrm{NH}_{4} \mathrm{OH}$ to 9.0 ) and methanol were used for elution. Gradient elution at flow rate $0.3 \mathrm{~mL} / \mathrm{min}$ started at $10 \%$ methanol and was raised to $55 \%$ within $25 \mathrm{~min}$, after which methanol concentration was raised to $100 \%$ within $5 \mathrm{~min}$. Methanol concentration was kept at $100 \%$ for $5 \mathrm{~min}$, then lowered to $10 \%$ in $5 \mathrm{~min}$, and equilibrated at $10 \%$ for $5 \mathrm{~min}$. Column temperature was set to $30^{\circ} \mathrm{C}$ and the injection volume was $10 \mu \mathrm{L}$.

2.6. Standard and Buffer Solutions. Stock solutions of the analytes at $1 \mathrm{mg} / \mathrm{mL}$ in the appropriate solvent (mixture of $\mathrm{MeOH}$ and $1 \mathrm{mM}$ ammonium acetate buffer with $0.1 \%$ formic acid, 20/80) were prepared. The stock solution for SDM was $0.5 \mathrm{mg} / \mathrm{mL}$ due to its poor solubility. The working standard solution contained 5 antimicrobials at $0.1 \mathrm{mg} / \mathrm{mL}$. From this solution dilution $(10 \mu \mathrm{g} / \mathrm{mL}$ and $1 \mu \mathrm{g} / \mathrm{mL})$ was made. The stock solution was stored at $-20^{\circ} \mathrm{C}$. Fresh working standard solutions were prepared daily.

2.7. Method Validation. The developed method was validated following Eurachem guidelines [50] and the linearity, limit of quantification, and process efficiency (recovery and matrix effect) were evaluated.

\section{Results and Discussion}

3.1. Liquid Extraction. The developed method is based on the combination of liquid extraction, SPE, and LC-MS analysis of a total of five antimicrobials. Antimicrobials from two classes, FQs and SAs, are structurally and chemically diverse. The variables optimized were extraction solvent, $\mathrm{pH}$, and homogenization. Hexane, chloroform, methanol, and acetonitrile were tested as extraction solvents. The organic solvent content in an extraction solvent was varied from 20 to $100 \%$. Extraction with chloroform and hexane gave the lowest overall antibiotic recoveries (1-2\%) for CIP and NOR. The extraction mixture's aqueous solution's $\mathrm{pH}$ varied from acidic (1\% acetic acid, $\mathrm{pH} 2.0$ ) to basic (5 mM ammonium acetate, $\mathrm{pH} 9.0$ (using $\mathrm{NH}_{4} \mathrm{OH}$ )) conditions. Extraction with acetonitrile was more efficient compared with methanol. The mixture of acetonitrile and $1 \%$ acetic acid (1/1) was finally chosen as an extraction solvent for simultaneous extraction of all the analytes of interest. During the optimization of liquid extraction, it was found that extraction efficiency increased when homogenization was used along with sonication and mixing. The increase of the time of liquid extraction stages did not increase extraction recoveries. In total, the time for a LE procedure was 17 minutes.

3.2. Solid Phase Extraction (SPE). After liquid extraction and centrifugation, the supernatant was separated and dried by nitrogen stream to remove acetonitrile. Remaining extracts were cleaned up with HLB SPE cartridges. The HLB cartridges enable retaining both hydrophilic and hydrophobic compounds [51] and give the highest recoveries for all of the analytes studied. The sample $\mathrm{pH}$ was adjusted by adding approximately $15 \mathrm{~mL}$ of $1 \%$ acetic acid. For elution, methanol was used.

3.3. LC-MS. Previously several buffer solutions and $\mathrm{pH}$ values were tested thoroughly for the reverse phase (RP) LC separation of named antibiotics [31]. Although the MS signal of analytes was higher using an eluent with a lower $\mathrm{pH}$ (ammonium acetate, formic acid with $\mathrm{pH} 2.8$ ), the separation of the compound was not followed. At higher $\mathrm{pH}$ values, the fluoroalcohol HFIP gave significantly better ionization efficiencies and better peak shapes, compared to acidic conditions and known buffer additives [47], and all 5 compounds had baseline separation for an antibiotic standard solution using RP column. For the LC analysis, the $5 \mathrm{mM}$ HFIP and gradient elution with methanol was used. The application demonstrates the successful separation of chosen compounds from the potato tubers extract (Figure 1).

HFIP as an eluent additive is predominantly protonated at $\mathrm{pH}$ 9.0. Therefore, the interaction with the nonpolar stationary phase is relatively strong [31, 52]. HFIP covers the C18 stationary phase with a fluorous layer [52], shifting the stationary phase properties nearer to a fluorinated stationary phase. Acting as a weak ion-pairing agent, HFIP allows the alternative interaction with structurally similar FQs [52]. Using HFIP as an eluent additive decreases the retention of SAs more than FQs. At pH 9.0, the FQs exist mostly in the zwitterionic forms. Therefore, the retention pattern of FQs is influenced both by the fluorous layer of the stationary phase and by the acid-base equilibrium. At the same time, the SAs $\mathrm{pKa}$ values are much lower than 9 and the mobile phase $\mathrm{pH}$ does not affect the retention changes strongly.

In order to attain higher selectivity for FQs, the separation of five antimicrobials was studied in the alkyl perfluorinated 


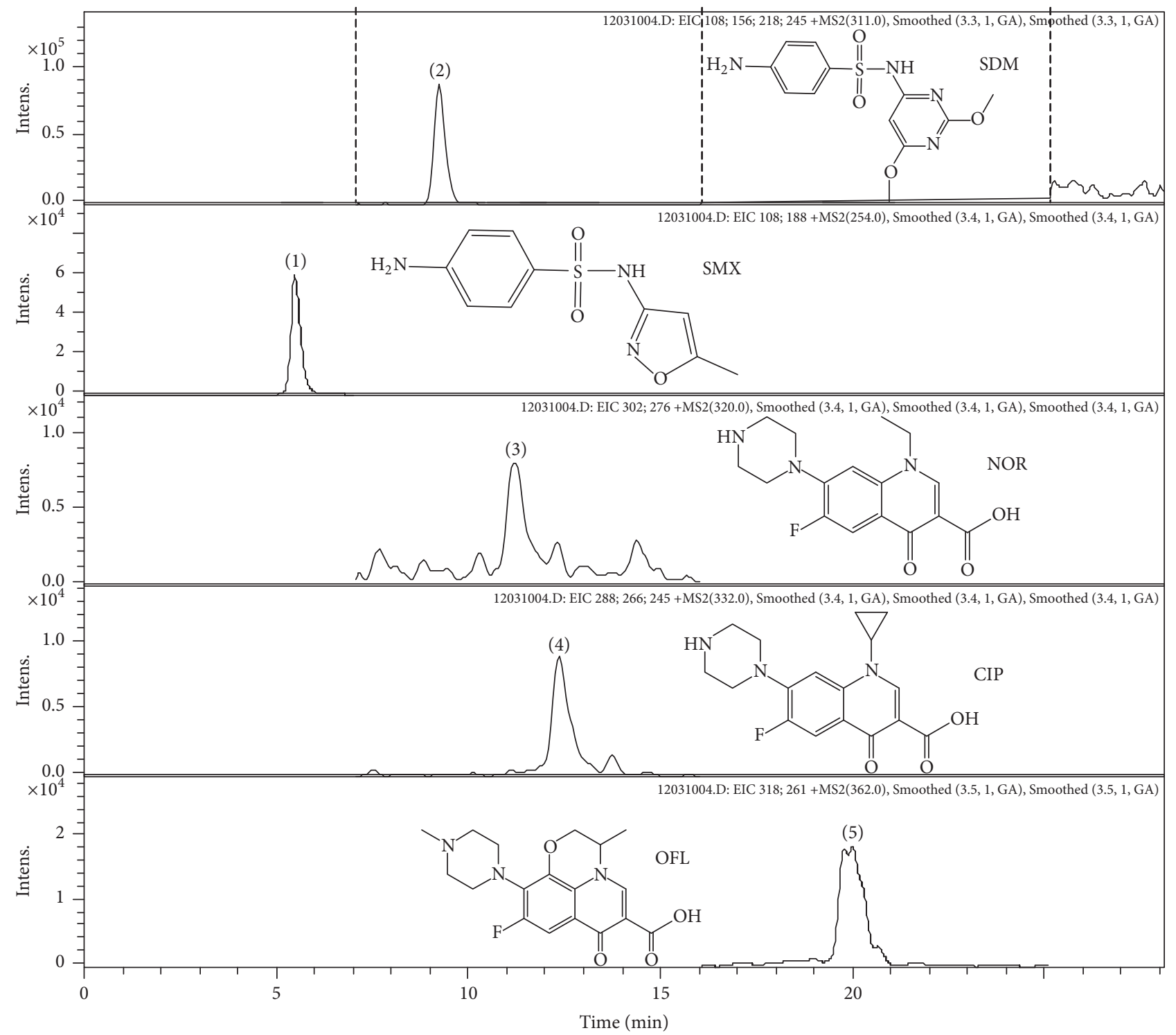

FIGURE 1: The chromatographic separation of antibiotic residues in potato tuber. Antimicrobials spiked in the LoQ level ((1) SMX $32.7 \mathrm{ng} / \mathrm{g}$; (2) SDM $17.8 \mathrm{ng} / \mathrm{g}$; (3) NOR $40.0 \mathrm{ng} / \mathrm{g}$; (4) CIP $27.2 \mathrm{ng} / \mathrm{g}$; (5) OFL $5.0 \mathrm{ng} / \mathrm{g}$ ). Eluent: $5 \mathrm{mM} \mathrm{HFIP}$ (pH 9) and MeOH. Analytical column: Waters XBridge C18 column $(150 \mathrm{~mm} \times 3 \mathrm{~mm}, 3.5 \mu \mathrm{m})$.

stationary phase Epic FO-LB C8. However, the SMX and SDM showed well-expressed peak shapes and had different retention; the FQs peaks were wide and shallow, having similar retention in the perfluorinated stationary phase (Figure 2). Fluorinated analytes retention on the fluorinated stationary phase is mainly influenced by the number of fluorine atoms in the analyte molecule [53]. The number of fluorine atoms in the three FQs studied is one and the structures of the molecules are similar. Therefore, the retention of the analytes on the fluorinated stationary phase is also similar. On the other hand, the ESI signal of the analytes should be enhanced under acidic conditions. The MS chromatogram of the FQs and SAs separation had a high noise level in the extracted ion chromatograms for FQs; the peaks were broad and partly overlapping (Figure 2). Neither better separation nor enhanced signal was obtained by optimization of the elution gradient or the buffer composition or $\mathrm{pH}$.

3.4. Method Validation. The described method was validated for the simultaneous determination of CIP, NOR, OFL, SDM, and SMX in plants. For calibration, antimicrobials and standard solutions were prepared in $10 \%$ methanol and water. The calibration graphs with peak area versus concentration were composed in concentration range $5-10,000 \mathrm{ng} / \mathrm{g}$ and were linear with $r^{2}>0.9998$. Extraction recovery was calculated from standard addition experiments. Extraction recoveries for all detected pharmaceuticals in all matrices varied from 54 to $98 \%$; the average recoveries are shown in Figure 3. Method validation was performed in the matrix which showed the lowest recovery: carrot roots in loamy 


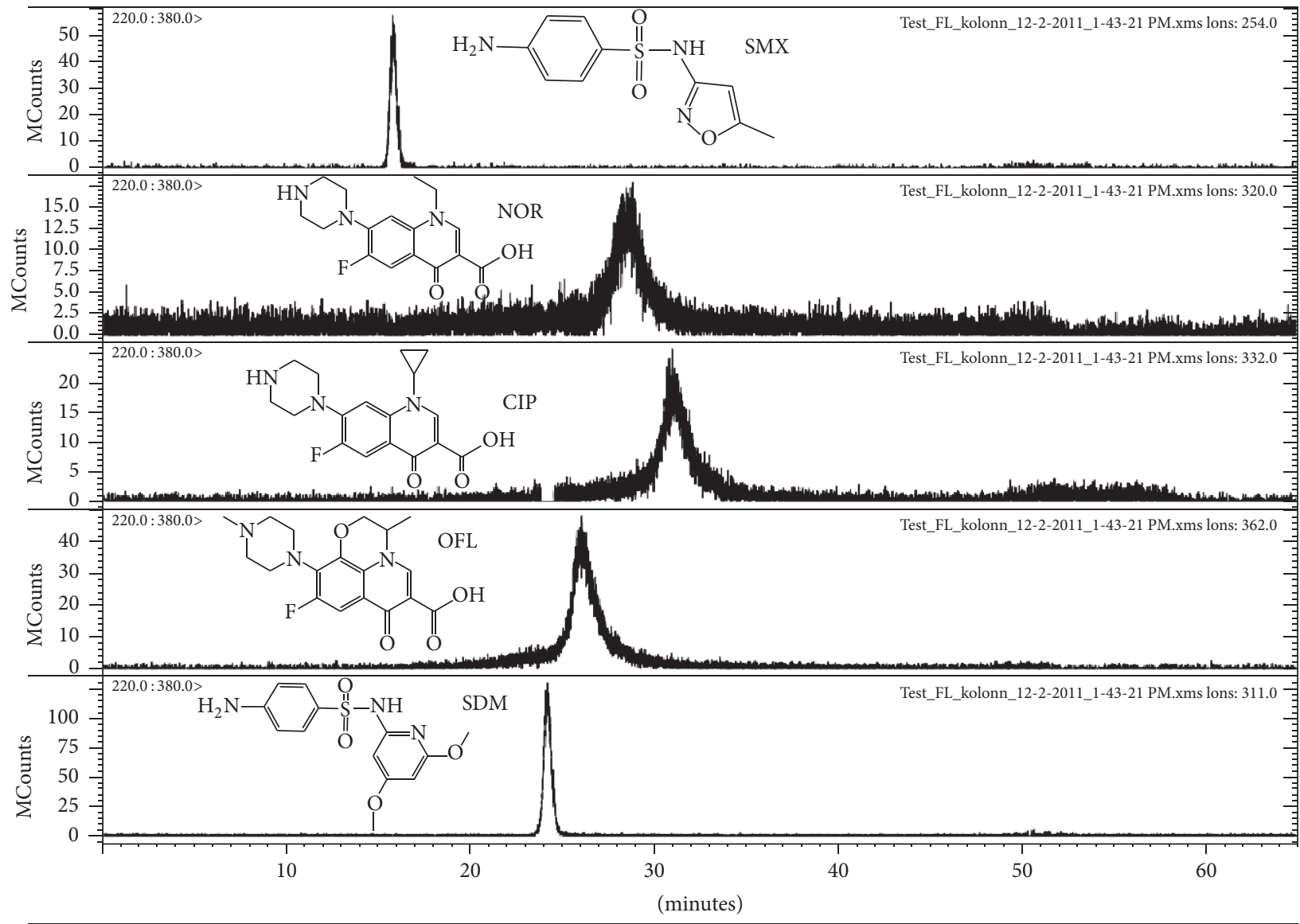

FIGURE 2: MS chromatogram for the standard solution of FQs and SAs (10 $\mu \mathrm{g} / \mathrm{g})$. Eluent: (ammonium acetate, formic acid pH 2.8$)$ and MeOH. Used analytical column: Epic FO-LB C8 column $(150 \mathrm{~mm} \times 3 \mathrm{~mm}, 3.5 \mu \mathrm{m})$.

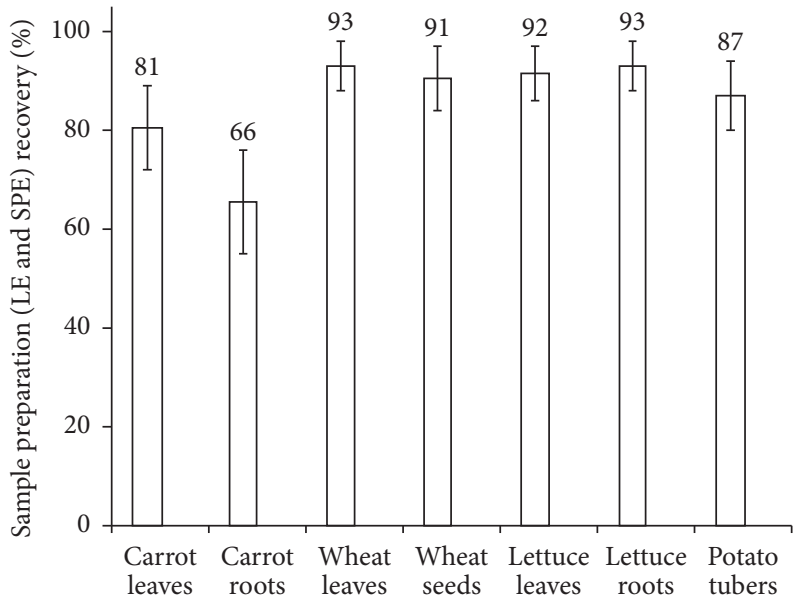

FIGURE 3: Average sample preparation (LE and SPE) recoveries $(n=$ 2) of 5 antimicrobials (CIP, ciprofloxacin; NOR, norfloxacin; OFL, ofloxacin; SDM, sulfadimethoxine; SMX, sulfamethoxazole) from different parts of food plants grown in loamy soil using LE and SPE. Error bars show the recovery ranges.

soil (recovery ranges 54-78\%, average recovery 66\%). A postextraction spike in three different concentrations over the calibration range (low, $5 \mathrm{ng} / \mathrm{g}$; medium, $250 \mathrm{ng} / \mathrm{g}$; and high,
$5,000 \mathrm{ng} / \mathrm{g}$ ) to the different plants did not show a significant matrix interference. The process efficiency was primarily influenced by the extraction recovery in the two steps (LLE and SPE) of the sample preparation.

The average recoveries of antimicrobials from carrot roots, as shown in Figure 4, were 73\% (CIP), 69\% (NOR), 76\% (OFL), 55\% (SDM), and 70\% (SMX). Standard deviations for the recoveries were $1 \%$ (CIP), $2 \%$ (NOR), $2 \%$ (OFL), $1 \%$ (SDM), and 1\% (SMX). The limits of quantifications (LoQs) were estimated as ten times the standard deviation from five replicate analyses of unspiked and spiked plant samples using HLB cartridges. LoQs were as follows: CIP 27.2; NOR 40.0; OFL 5.0; SDM 17.8; and SMX $32.7 \mathrm{ng} / \mathrm{g}$. The relative standard deviations (RSD) were, respectively, $0.27,0.40,0.05,0.18$, and 0.32 percent.

\section{Conclusion}

Plant uptake of pharmaceutical residues, present (even in very small amounts) in soils fertilized with sewage sludge compost, is an obvious reality. As antimicrobials consumed in very small amounts with everyday food can initiate strains of resistant bacteria in human and animal organisms, the high sensitivity of their detection methodology is of utmost 


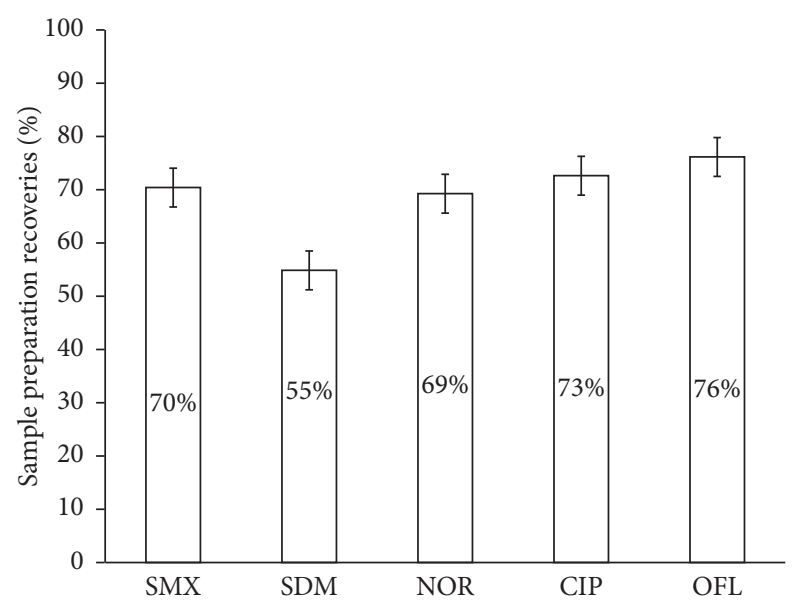

FIgURE 4: Average sample preparation recoveries for 5 antimicrobials from carrot roots using LE and SPE. Matrix: carrot roots. Error bars are 2 times standard deviation. CIP, ciprofloxacin; NOR, norfloxacin; OFL, ofloxacin; SDM, sulfadimethoxine; SMX, sulfamethoxazole.

importance. Improved separation of the groups of structurally similar antimicrobials, fluoroquinolones (FQs) and sulfonamides (SAs), and enhanced MS signal intensities were achieved as a result of this work, by using an eluent additive HFIP in regular C18 stationary phase. The developed and validated method described in the current paper has turned out to be an efficient tool for detecting the concentrations of antimicrobials in food plants fertilized with sewage sludge compost.

\section{Conflicts of Interest}

The authors declare that they have no conflicts of interest.

\section{Acknowledgments}

This work was supported by Grant no. 7127 from the Estonian Science Foundation, by the Target Financing Project no. SF0180061s08 from the Ministry of Education and Science of Estonia, and by Estonian Environmental Investment Centre. The authors thank Ms. Karin Muoni and Mr. Andre Litvin for correcting this manuscript.

\section{References}

[1] E. Meyer, P. Gastmeier, M. Deja, and F. Schwab, "Antibiotic consumption and resistance: data from Europe and Germany," International Journal of Medical Microbiology, vol. 303, no. 6, pp. 388-395, 2013.

[2] K. J. Forsberg, A. Reyes, B. Wang, E. M. Selleck, M. O. A. Sommer, and G. Dantas, "The shared antibiotic resistome of soil bacteria and human pathogens," Science, vol. 337, no. 6098, pp. 1107-1111, 2012.

[3] K. Fent, A. A. Weston, and D. Caminada, "Ecotoxicology of human pharmaceuticals," Aquatic Toxicology, vol. 76, no. 2, pp. 122-159, 2006.
[4] S. Zühlke, U. Dünnbier, and T. Heberer, "Detection and identification of phenazone-type drugs and their microbial metabolites in ground and drinking water applying solid-phase extraction and gas chromatography with mass spectrometric detection," Journal of Chromatography A, vol. 1050, no. 2, pp. 201-209, 2004.

[5] K.-R. Kim, G. Owens, Y. S. Ok, W.-K. Park, D. B. Lee, and S.I. Kwon, "Decline in extractable antibiotics in manure-based composts during composting," Waste Management, vol. 32, no. 1, pp. 110-116, 2012.

[6] C. E. Rodríguez-Rodríguez, E. Barón, P. Gago-Ferrero et al., "Removal of pharmaceuticals, polybrominated flame retardants and UV-filters from sludge by the fungus Trametes versicolor in bioslurry reactor," Journal of Hazardous Materials, vol. 233-234, pp. 235-243, 2012.

[7] R. Reichel, I. Rosendahl, E. T. H. M. Peeters et al., "Effects of slurry from sulfadiazine-(SDZ) and difloxacin-(DIF) medicated pigs on the structural diversity of microorganisms in bulk and rhizosphere soil," Soil Biology and Biochemistry, vol. 62, pp. 8291, 2013.

[8] E. Haiba, L. Nei, M. Ivask et al., "Sewage sludge composting and fate of pharmaceutical residues-recent studies in Estonia," Agronomy Research, vol. 14, pp. 1583-1600, 2016.

[9] O. Borgman and B. Chefetz, "Combined effects of biosolids application and irrigation with reclaimed wastewater on transport of pharmaceutical compounds in arable soils," Water Research, vol. 47, no. 10, pp. 3431-3443, 2013.

[10] D. Ašperger, V. Tišler, M. Zrnčić et al., "HPLC-DAD-FLD determination of veterinary pharmaceuticals in pharmaceutical industry wastewater with precolumn derivatization using fluorescamine," Chromatographia, vol. 77, no. 15, pp. 1059-1066, 2014.

[11] M. Motoyama, S. Nakagawa, R. Tanoue, Y. Sato, K. Nomiyama, and R. Shinohara, "Residues of pharmaceutical products in recycled organic manure produced from sewage sludge and solid waste from livestock and relationship to their fermentation level," Chemosphere, vol. 84, no. 4, pp. 432-438, 2011.

[12] A. Gonzalez-Martinez, A. Rodriguez-Sanchez, M. V. MartinezToledo et al., "Effect of ciprofloxacin antibiotic on the partialnitritation process and bacterial community structure of a submerged biofilter," Science of the Total Environment, vol. 476477, pp. 276-287, 2014.

[13] C. E. Rodríguez-Rodríguez, A. Jelić, M. Llorca et al., "Solidphase treatment with the fungus Trametes versicolor substantially reduces pharmaceutical concentrations and toxicity from sewage sludge," Bioresource Technology, vol. 102, no. 10, pp. 5602-5608, 2011.

[14] T. Vasskog, O. Bergersen, T. Anderssen, E. Jensen, and T. Eggen, "Depletion of selective serotonin reuptake inhibitors during sewage sludge composting," Waste Management, vol. 29, no. 11, pp. 2808-2815, 2009.

[15] W. Peysson and E. Vulliet, "Determination of 136 pharmaceuticals and hormones in sewage sludge using quick, easy, cheap, effective, rugged and safe extraction followed by analysis with liquid chromatography-time-of-flight-mass spectrometry," Journal of Chromatography A, vol. 1290, pp. 46-61, 2013.

[16] M. Lillenberg, S. Yurchenko, K. Kipper et al., "Presence of fluoroquinolones and sulfonamides in urban sewage sludge and their degradation as a result of composting," International Journal of Environmental Science and Technology, vol. 7, no. 2, pp. 307-312, 2010.

[17] K. Kipper, K. Herodes, M. Lillenberg, L. Nei, E. Haiba, and S. V. Litvin, "Plant uptake of some pharmaceuticals commonly 
present in sewage sludge compost," in Proceedings of the 2nd International Conference on Chemical, Biological and Environmental Engineering (ICBEE '10), pp. 261-264, Cairo, Egypt, November 2010.

[18] L. Nei, E. Haiba, S. Kutti, M. Lillenberg, K. Kipper, and K. Herodes, "Sewage sludge compost, microbial activity and pharmaceuticals," AWERProcedia Advances in Applied Sciences, vol. 3, pp. 30-37, 2014.

[19] A. B. A. Boxall, P. Johnson, E. J. Smith, C. J. Sinclair, E. Stutt, and L. S. Levy, "Uptake of veterinary medicines from soils into plants," Journal of Agricultural and Food Chemistry, vol. 54, no. 6, pp. 2288-2297, 2006.

[20] J. Qiting and Z. Xiheng, "Combination process of anaerobic digestion and ozonization technology for treating wastewater from antibiotics production," Water Treat, vol. 3, pp. 285-291, 1988.

[21] M. Ravina, L. Campanella, and J. Kiwi, "Accelerated mineralization of the drug Diclofenac via Fenton reactions in a concentric photo-reactor," Water Research, vol. 36, no. 14, pp. 3553-3560, 2002.

[22] H. F. Schröder, "Mass spectrometric monitoring of the degradation and elimination efficiency for hardly eliminable and hardly biodegradable polar compounds by membrane bioreactors," Water Science and Technology, vol. 46, no. 3, pp. 57-64, 2002.

[23] T. A. Ternes, J. Stüber, N. Herrmann et al., "Ozonation: a tool for removal of pharmaceuticals, contrast media and musk fragrances from wastewater?" Water Research, vol. 37, no. 8, pp. 1976-1982, 2003.

[24] C. Lee, C. Schmidt, J. Yoon, and U. Von Gunten, "Oxidation of N-nitrosodimethylamine (NDMA) precursors with ozone and chlorine dioxide: kinetics and effect on NDMA formation potential," Environmental Science and Technology, vol. 41, no. 6, pp. 2056-2063, 2007.

[25] C. Trautwein, K. Kümmerer, and J. W. Metzger, "Aerobic biodegradability of the calcium channel antagonist verapamil and identification of the dead-end metabolite 2-(3,4-dimethoxyphenyl)-2isopropyl-5-(methylamino)pentane nitrile," Chemosphere, vol. 72, pp. 442-450, 2008.

[26] F. Méndez-Arriaga, S. Esplugas, and J. Giménez, "Photocatalytic degradation of non-steroidal anti-inflammatory drugs with $\mathrm{TiO}_{2}$ and simulated solar irradiation," Water Research, vol. 42, no. 3, pp. 585-594, 2008.

[27] EMEA/MRL/026/95, Committee for Veterinary Medicinal Products, Sulphonamides (2), Summary report, 1995, http://www .ema.europa.eu/ema/index.jsp?curl=pages/includes/document/ document_detail.jsp?webContentId=WC500015931\&murl= menus/medicines/medicines.jsp\&mid=WC0b01ac058009a3dc.

[28] EMEA/MRL/820/02 - FINAL, Committee for Veterinary Medicinal Products, Enrofloxacin (extension to all food producing species), Summary report (5), 2002, http://www.ema.europa.eu/ docs/en_GB/document_library/Maximum_Residue_Limits_-_ Report/2009/11/WC500014151.pdf.

[29] E. M. Golet, A. Strehler, A. C. Alder, and W. Giger, "Determination of fluoroquinolone antibacterial agents in sewage sludge and sludge-treated soil using accelerated solvent extraction followed by solid-phase extraction," Analytical Chemistry, vol. 74, no. 21, pp. 5455-5462, 2002.

[30] J. L. Stevens, G. L. Northcott, G. A. Stern, G. T. Tomy, and K. C. Jones, "PAHs, PCBs, PCNs, organochlorine pesticides, synthetic musks, and polychlorinated n-alkanes in U.K. sewage sludge: Survey results and implications," Environmental Science and Technology, vol. 37, no. 3, pp. 462-467, 2003.
[31] K. Kipper, K. Herodes, I. Leito, and L. Nei, “Two fluoroalcohols as components of basic buffers for liquid chromatography electrospray ionization mass spectrometric determination of antibiotic residues," Analyst, vol. 136, no. 21, pp. 4587-4594, 2011.

[32] A. Göbel, C. S. McArdell, M. J.-F. Suter, and W. Giger, "Trace determination of macrolide and sulfonamide antimicrobials, a human sulfonamide metabolite, and trimethoprim in wastewater using liquid chromatography coupled to electrospray tandem mass spectrometry," Analytical Chemistry, vol. 76, no. 16, pp. 4756-4764, 2004.

[33] A. Göbel, A. Thomsen, C. S. McArdell et al., "Extraction and determination of sulfonamides, macrolides, and trimethoprim in sewage sludge," Journal of Chromatography A, vol. 1085, no. 2, pp. 179-189, 2005.

[34] C. A. Kinney, E. T. Furlong, S. D. Zaugg et al., "Survey of organic wastewater contaminants in biosolids destined for land application," Environmental Science and Technology, vol. 40, no. 23, pp. 7207-7215, 2006.

[35] T. L. Jones-Lepp and R. Stevens, "Pharmaceuticals and personal care products in biosolids/sewage sludge: the interface between analytical chemistry and regulation," Analytical and Bioanalytical Chemistry, vol. 387, no. 4, pp. 1173-1183, 2007.

[36] J. Heidler, A. Sapkota, and R. U. Halden, "Partitioning, persistence, and accumulation in digested sludge of the topical antiseptic triclocarban during wastewater treatment," Environmental Science and Technology, vol. 40, no. 11, pp. 3634-3639, 2006.

[37] A. Kaleta, M. Ferdig, and W. Buchberger, "Semiquantitative determination of residues of amphetamine in sewage sludge samples," Journal of Separation Science, vol. 29, no. 11, pp. 16621666, 2006.

[38] T. Okuda, N. Yamashita, H. Tanaka, H. Matsukawa, and K. Tanabe, "Development of extraction method of pharmaceuticals and their occurrences found in Japanese wastewater treatment plants," Environment International, vol. 35, no. 5, pp. 815-820, 2009.

[39] L. Migliore, G. Brambilla, S. Cozzolino, and L. Gaudio, "Effect on plants of sulphadimethoxine used in intensive farming (Panicum miliaceum, Pisum sativum and Zea mays)," Agriculture, Ecosystems and Environment, vol. 52, no. 2-3, pp. 103-110, 1995.

[40] L. Migliore, G. Brambilla, P. Casoria, C. Civitareale, S. Cozzolino, and L. Gaudio, "Effect of sulphadimethoxine contamination on barley (Hordeum distichum L., Poaceae, Liliopsida)," Agriculture, Ecosystems and Environment, vol. 60, no. 2-3, pp. 121-128, 1996.

[41] G. Brambilla, P. Casoria, C. Civitareale, S. Cozzolino, L. Gaudio, and L. Migliore, "Sulphadimetoxine as environmental tracer to evaluate phytotoxity in crop," in Proceedings of the Conference on Residues of Veterinary Drugs in Food, pp. 292-295, Veldhoven, Netherlands, 1996.

[42] P. K. Jjemba, "The potential impact of veterinary and human therapeutic agents in manure and biosolids on plants grown on arable land: a review," Agriculture, Ecosystems and Environment, vol. 93, no. 1-3, pp. 267-278, 2002.

[43] L. Migliore, S. Cozzolino, and M. Fiori, "Phytotoxicity to and uptake of enrofloxacin in crop plants," Chemosphere, vol. 52, no. 7, pp. 1233-1244, 2003.

[44] M. Lillenberg, M. Roasto, and T. Püssa, "Drug residues in environment. Estimation of fluoroquinolones in soil and food plants," Journal of Agricultural Science, vol. 14, pp. 13-26, 2003. 
[45] H. Dolliver, K. Kumar, and S. Gupta, "Sulfamethazine uptake by plants from manure-amended soil," Journal of Environmental Quality, vol. 36, no. 4, pp. 1224-1230, 2007.

[46] L. Michelini, R. Reichel, W. Werner, R. Ghisi, and S. ThieleBruhn, "Sulfadiazine uptake and effects on Salix fragilis L. and Zea mays L. plants," Water, Air, and Soil Pollution, vol. 223, no. 8, pp. 5243-5257, 2012.

[47] A. Thomsen, A. Göbel, Mc. Ardell C et al., "Determination of sulfonamide and macrolide antibiotics in sewage sludge using accelerated solvent extraction and LC-MS/MS," in Proceeddings of the Poseidon Symposium, Braunschweig, Germany, 2003.

[48] M. Lillenberg, S. Yurchenko, K. Kipper et al., "Simultaneous determination of fluoroquinolones, sulfonamides and tetracyclines in sewage sludge by pressurized liquid extraction and liquid chromatography electrospray ionization-mass spectrometry," Journal of Chromatography A, vol. 1216, no. 32, pp. 59495954, 2009.

[49] M. Lillenberg, Residues of some pharmaceuticals in sewage sludge in Estonia, their stability in the environment and accumulation into food plants via fertilizing: PhD thesis in environmental protection [Ph.D. thesis], Estonian University of Life Sciences, Tartu, Estonia, 2011.

[50] H. Holcombe, Ed., EURACHEM Guide: The Fitness for Purpose of Analytical Methods-A Laboratory Guide to Method Validation and Related Topics, LGC, Teddington, UK, 1998.

[51] M. E. Lindsey, M. Meyer, and E. M. Thurman, "Analysis of trace levels of sulfonamide and tetracycline antimicrobials in groundwater and surface water using solid-phase extraction and liquid chromatography/mass spectrometry," Analytical Chemistry, vol. 73, no. 19, pp. 4640-4646, 2001.

[52] K. Kipper, K. Herodes, and I. Leito, "Fluoroalcohols as novel buffer components for basic buffer solutions for liquid chromatography electrospray ionization mass spectrometry: retention mechanisms," Journal of Chromatography A, vol. 1218, no. 45, pp. 8175-8180, 2011.

[53] J. A. Gladysz, D. P. Curran, and I. T. Horvath, Handbook of Fluorous Chemisry, Wiley, New York, NY, USA, 2004. 

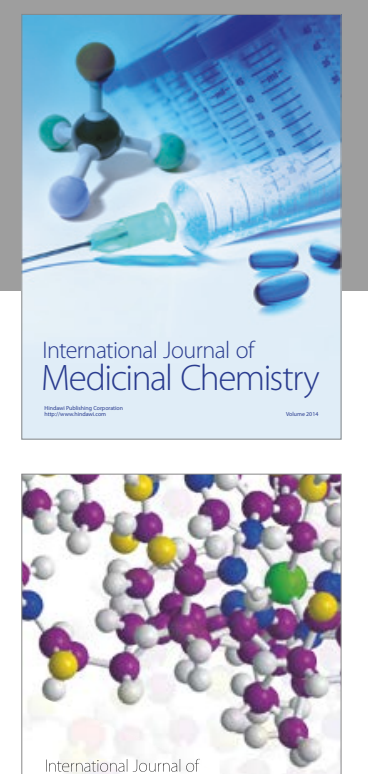

Carbohydrate Chemistry

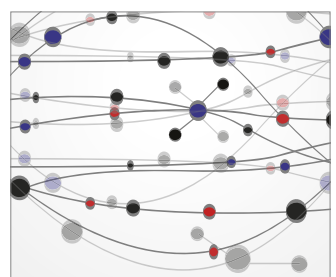

The Scientific World Journal
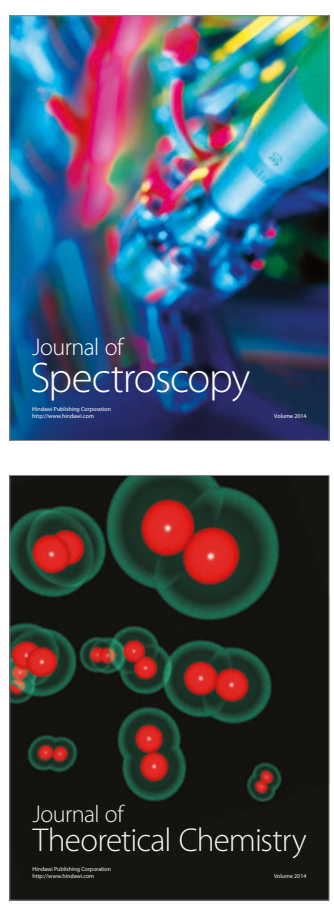
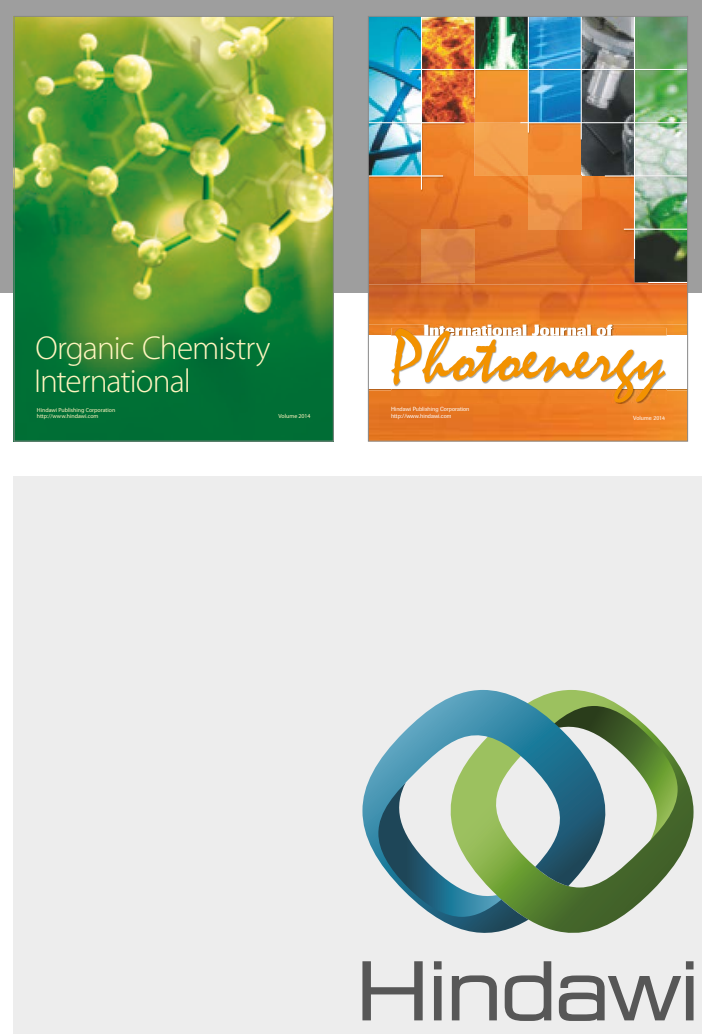

Submit your manuscripts at

https://www.hindawi.com

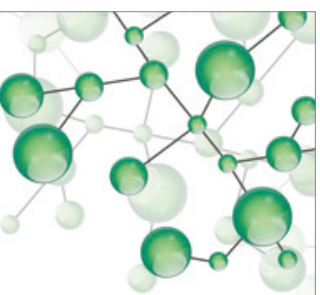

International Journal of

Inorganic Chemistry

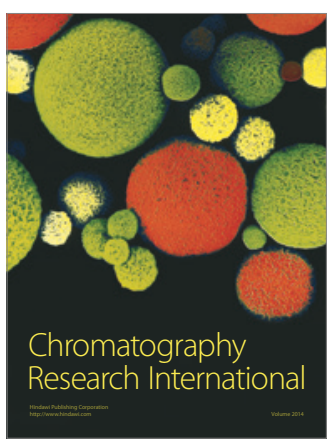

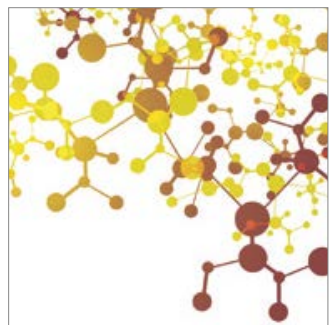

Applied Chemistry
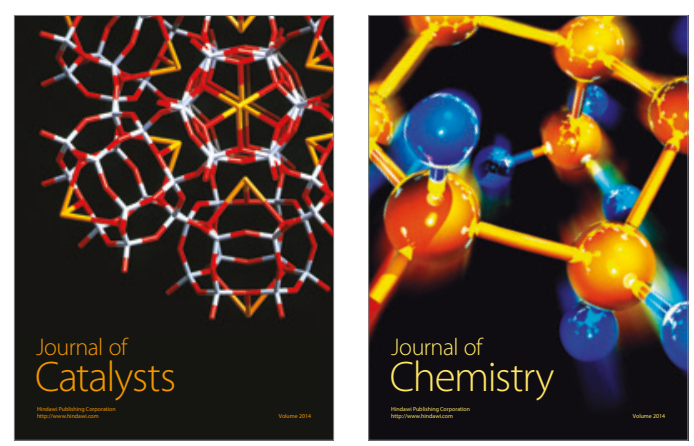
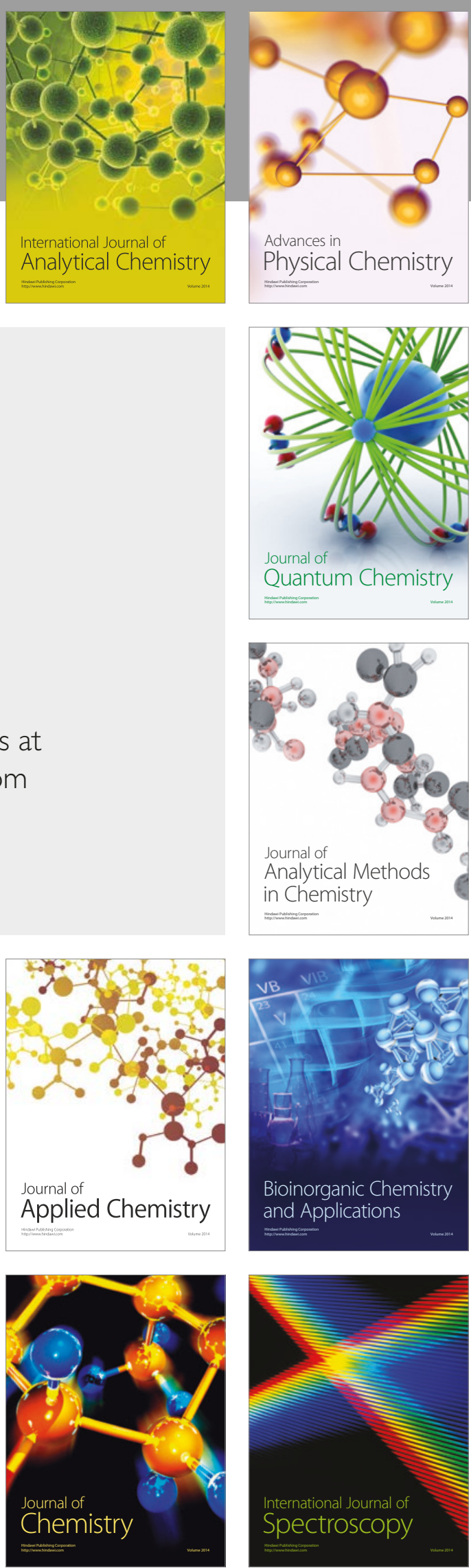